\title{
EFFICIENCY OF FEEDING GRADED LEVELS OF SOME HONEY BEE PRODUCTS (PROPOLIS, BEE-POLLEN AND HONEY) AS ALTERNATIVE TO ANTIBIOTIC ON INTESTINAL MICROFLORO OF BROILER CHICKENS
}

\section{A.I. El-Faham, F. Abd El-Azeem, N.M. El-Medany and M.M. Hamed}

Poultry Production Department, Faculty of Agriculture, Ain Shams University, Cairo, Egypt

Three experiments were conducted to examine effects of using graded levels of propolis $(\mathrm{PR})$, Bee-pollen (BP) and honey (BH) in comparison to antibiotics (Erythromycin, ER) or (Colistinsulphate, CS) in broiler diets, on intestinal microflora population up to 35 days of age.

One hundred and fifty, unsexed one day old Cobb chicks were weighed and randomly allocated into a completely randomized design in each experiment (Exp); 1,2 or 3, (five treatments, three replicates with ten chicks in each experiment).

The experimental diets were as follows: basal diets without supplementation control (Exp1: Exp3), $0.275 \%$ ER, $\mathrm{T}_{1}$ (Exp1 and 3) or $0.01 \% \mathrm{CS}$, T1 (Exp2), T2, T3 and T4content the supplementation of PR (Exp1) or BP (Exp2) at the levels of $0.05,0.10$ and $0.20 \%$, respectively, while in (Exp3) basal diets of T2: T4 supplemented with $0.10,0.15$ and $0.20 \% \mathrm{BH}$, respectively. Results indicated that different levels of PR, BP or BH in Exp1: Exp3, linearly reduced counts of total viable bacteria compared with control, ER or CS treatments. At the same time, it tended to show a reduction in total count of pathogenic bacteria representing $E$. coli for CS or different levels of PR, BP or BH compared with their control groups.

Additionally, using CS or different levels of PR, BP and BH presented positive effects on Salmonella counts in small intestine as it was not detected, when compared with their control treatments. Also, it is obvious that high levels of (PR or BP) and low level of BH increased Lactobacillus count compared with other dietary treatments of control, ER or CS.

It can be concluded that treating diets by $\mathrm{PR}, \mathrm{BP}$ and $\mathrm{BH}$ could be used as alternative to antibiotics (ER or CS) in chicks' diets during 1-35 days of age with positive effect on intestinal microflora population. 